\title{
Gênese de uma disciplina: a tradutologia
}

\author{
Inês Oseki-Dépré*
}

Numa carta de 12 de novembro de 2003, Henri Meschonnic ${ }^{1}$ se indigna - o que não é raro da parte desse excelente teórico, crítico, tradutor e poeta. Ele manifesta sua indignação após ter lido meu segundo livro sobre a tradução literária ${ }^{2}$, no qual me esforço em traçar a gênese de uma teoria da tradução que vai de Walter Benjamin até nossos dias.

O capítulo consagrado a Antoine Berman pertence à primeira parte do livro, no interior da seção "Entre hermenêutica e poética", e vem após o capítulo dedicado a Walter Benjamin e à bipolaridade da tarefa do tradutor. O capítulo seguinte é dedicado à Meschonnic e se intitula "Uma poética militante: Henri Meschonnic".

O lugar de Berman logo a seguir à apresentação da "tarefa do tradutor" é natural, na medida em que ele se inspira em grande parte da posição dominante na teoria do filósofo alemão, no tocante à literalidade, à letra, à essência do traduzir.

Em sua carta (12/11/2003), Meschonnic retraça, por outro lado, as diferentes etapas de sua relação a Antoine Berman, cujo doutorado, sob sua direção, contém os elementos essenciais do que se tornaria sua primeira obra, A prova do estrangeiro (L'épreuve de l'étranger, 1984), que, segundo Meschonnic, deve muito ao orientador que ele foi.

\footnotetext{
* Professora emérita de Literatura Comparada, Universidade Aix-Marselha, laboratório CIELAM.

1 Henri Meschonnic (1932-2009), teórico, crítico, tradutor e poeta, é autor de inúmeras obras sobre a tradução literária, sobre o ritmo e a rima, de traduções da Bíblia, e de antologias poéticas, tendo recebido vários prêmios literários (Max-Jacob, 1972; Mallarmé, 1986)

2 De Walter Benjamin a nossos dias (De Walter Benjamin à nos jours), a ser lançado em março próximo pela Editora da Universidade de Brasília em colaboração com a Fundação Guilherme de Almeida.
} 
A importância dos trabalhos de Henri Meschonnic é indiscutível quer para Antoine Berman quer para mim, e pouco importa aqui a maior ou menor influência que teóricos, tradutores ou poetas exerceram sobre nosso trabalho. É verdade que Antoine Berman, enquanto filósofo, se atém mais a uma ética do traduzir que o leva a condenar as tendências deformantes da tradução e explica a sua maneira hermenêutica de se interessar pelos textos, estando menos preocupado com a forma do original, que, para mim, foi sempre prioritária.

No meu entender, entretanto, a importância magna do trabalho de Antoine Berman foi a de definir o território da tradução, de inaugurar um domínio epistemológico até então inexistente, e que ele chamou de "tradutologia"3.

Na verdade, o termo já era utilizado por certos linguistas da Escola de Intérpretes ou por outros teóricos, como Jean-René Ladmiral ${ }^{4}$, mas numa acepção diferente, que Antoine Berman vai desenvolver longamente no seu Relatório de Habilitação a Dirigir Pesquisas 5 .

A tradutologia bermaniana procura delimitar o estatuto epistemológico e teórico da reflexão sobre a tradução e clarificar as relações dessa forma de saber com as outras disciplinas. ${ }^{6}$ Nesse sentido, ela cria um espaço múltiplo e transdisciplinar no qual a tradução ganha uma visibilidade outra, um estatuto autônomo, não mais como um procedimento ou mero meio de acesso a outras línguas mas como entidade, dotada de um Sujeito, ou melhor "como sujeito de saber, como origem e fonte de saber"7, o que permitirá amplos desenvolvimentos.

Como já tive ocasião de abordar amplamente os diversos aspectos da tradutologia bermaniana em meus trabalhos ulteriores sobre a tradução

\footnotetext{
3 Tradutologia: "reflexão da tradução sobre si mesma a partir de sua natureza de experiência", Tours de Babel, Mauvezin, TER (Trans-Europe-Repress), p. 39.

${ }^{4}$ Jean-René Ladmiral (1942, em Lisieux) é um filósofo, tradutor e crítico, famoso pela sua obra Théorèmes pour la traduction, Paris, Payot, 1979.

${ }^{5}$ HDR (Habilitation à Diriger des Recherches) é um concurso necessário para a titulação de um docente universitário, no qual o candidato apresenta um memorial inédito sobre o objeto de suas pesquisas.

${ }^{6}$ Ver Vanghélis Bitsoris, "Le projet de traductologie d'Antoine Berman", in La traduction - poésie, Presses Universitaires de Strasburg, 1999 (dir. Martine Broda), p. 49- 67.

${ }^{7}$ Antoine Berman, citado por Vanghélis Bitsoris, op. cit., p. 54.
} 
(1999 e 2007) ${ }^{8}$, proponho aqui o texto da minha palestra em Arles, no qual eu dialogo com Antoine Berman em testemunho de nossas "afinidades eletivas", mas no qual já transparece o pensamento de Haroldo de Campos, outro grande "tradutólogo"...

Antoine Berman e eu nos conhecemos em 1982, no lançamento de Premières Histoires, de João Guimarães Rosa, que traduzi para a Editora Anne Marie Métailié. Veio me cumprimentar pelo meu trabalho, que, segundo ele, correspondia exatamente à visão que tinha da tradução. Foi o início de uma grande amizade, rica de trocas e de cumplicidade. E logo a seguir, ele me enviou o texto de Walter Benjamin, "La tâche du traducteur", para reforçar seu ponto de vista. Devo a ele essa descoberta que muito me sustentou durante toda a minha vida de crítica e de tradutora literária.

Em 1985, ainda titular do ensino secundário, mas já diretora de um seminário de tradução literária na Universidade de Provença ${ }^{9}$, participei das segundas assembleias da tradução literária ${ }^{10}$, ocorridas em Arles, sob a égide do Collège International des Traducteurs Littéraires (CITL), com uma palestra sobre a tradução e a literalidade. Cumpre-se acrescentar que, embora hoje as coisas pareçam evidentes, naquela época, o que eu disse não foi do agrado da maioria dos tradutores, antes, chocou. Mandei o texto para Antoine Berman, que me respondeu por de maneira encorajadora.

Apresento aqui o texto da palestra ${ }^{11}$ :

\footnotetext{
8 Inês Oseki-Dépré, Théories et pratiques de la traduction littéraire, Paris, Armand Colin, 1999 (ver “Théories prescriptives") e De Walter Benjamin à nos jours, Paris, Honnoré Champion, 2007. Os dois títulos serão lançados em português este ano pela Editora da UnB juntamente com a Casa Guilherme de Almeida.

${ }_{9}^{9}$ Antoine Berman foi diretor do mesmo programa, sob a égide do Collège International de Philosophie (criado por Jean-Pierre Faye, Jacques Derrida, entre outros), administrando seus cursos em Buenos Aires. ${ }^{10}$ Ver "La lettre de l'étranger: remarques sur le concept de littéralité", em Actes des Deuxièmes assises de la traduction littéraire, Actes Sud - Atlas, 1985.

${ }^{11}$ Note-se que o texto, que transcrevo integralmente, data de $1984 \mathrm{e}$, portanto, hoje muito do que foi dito pode parecer evidência...
} 
"A letra (carta) do estrangeiro/Observações sobre o conceito de literalidade"

\section{Preliminares}

A tradução está incluída desde os primórdios numa tal dualidade que é difícil comentá-la sem levar em conta a oposição que se apresenta a cada instante entre: o Mesmo e o Outro; o Bom e o Mau; o fiel e o infiel; a prosa e a poesia; o transparente e o opaco; o clássico e o moderno; em suma, entre o traduttore e o traditore, a Übertragung (Interpretação) e a Übersetzung (Tradução), entre to translate e to traduce, etc.

De um modo geral, pode-se dizer que hoje em dia, a alternativa que se depreende no plano da prática, i.e., o do objeto, recobre de uma maneira ou de outra as oposições acima citadas, como sendo a que se coloca entre:

Uma tradução voltada para o público, o consumidor-editor, ou, em outras palavras, a estandardização da literatura estrangeira a partir do preceito de São Jerônimo:

"Non verbum e verbo, sed sensum exprimere de sensu" - preocupação eminente, aceita ou recusada, da tradução romanesca;

Uma tradução voltada para a obra, a criação, a expressão pessoal do autor e cujo fundamento teórico poderia ser a questão axiomática de Benjamin:

“Mas, se ela (a tradução) fosse destinada ao leitor, seria preciso que o original também o fosse. Se o original não foi feito para isso, como poderia se compreender então a tradução a partir dessa relação?", que é a questão posta à Modernidade.

Por essa alternativa, esquematizada de maneira grosseira, o pensamento contemporâneo se interessa desde alguns anos, a época atual se encontrando particularmente sensibilizada pela questão do estrangeiro, do Outro, da troca (mesmo da miscigenação) das culturas, ou pelo problema dos refugiados, exilados, e outros... e, embora a primeira opção permaneça basicamente dominante e massiva, obedecendo a critérios econômicos (ideológicos, comerciais), uma tendência em direção à segunda opção 
começa a aparecer. Pois, mesmo na televisão, lugar consensual, não se ouve dizer que a questão da tradução adquiriu maior importância?

O que é certo, é que a tomada de consciência da complexidade da tradução como operação - em suas premissas, efeitos, finalidades - e da necessidade da reflexão que essa atividade impõe é doravante inevitável ${ }^{12}$.

Isso se verifica principalmente no caso de prevalecer a segunda opção: traduzir tendo em vista a palavra do autor e de sua inscrição na literatura.

Mister é, portanto, acrescentar algumas palavras sobre a reflexão como modo de conhecimento e sobre a necessidade de uma análise rigorosa como modo de acesso a uma prática tão necessária quanto a tradução, principalmente porque, desde sua aparição, ela permaneceu essencialmente intuitiva e empírica.

Num segundo tempo, sobre o que se poderia chamar de parâmetros, dos quais dois estão no fundamento da tarefa do tradutor literário contemporâneo, a saber:

(o respeito à) letra;

a abertura (permeabilidade) à estranheza do texto original.

A reflexão

Em sua introdução à "Tarefa do tradutor" ("Au dessus des fragments d'um langage plus grand"13,) Michel Cresta não hesita em afirmar - com toda a razão - que "antes de ser, toda tradução é antes de tudo teoria da tradução" e que "todo texto traduzido é secundário em relação a uma construção anterior, um modelo teórico". Essa posição, Antoine Berman modula, sem recusá-la completamente, ao dizer: "A tradução pode muito bem passar sem teoria, mas não sem pensamento"14. Isso significa duas coisas:

(a) que se torna cada vez mais difícil de traduzir sem pensar a tradução;

(b) que se torna impossível hoje em dia traduzir sem se encontrar num pensamento da tradução.

\footnotetext{
${ }^{12}$ Antoine Berman, op. cit., p. 37.

${ }^{13}$ Littoral, n. 13, p. 53.

${ }^{14}$ Antoine Berman, op. cit., p. 39.
} 
Em outras palavras, expressamente ou não, toda tradução - seja ela a única a ser realizada pelo tradutor num momento dado da sua história é já um "pensamento" consciente ou inconsciente da tradução e se inscreve numa opção existente, a menos que ela inaugure a opção que ela realiza.

E, embora, como assinala Antoine Berman, não nos situemos no interior de uma ciência, antes, de um domínio próximo da filosofia ou da psicanálise - que não tenha como finalidade de definir fórmulas ou categorias precisas sobre a questão - , pode-se tentar, no interior mesmo desse domínio de reflexão ligado à experiência (domínio de uma tradutologia), levar mais longe não só essa reflexão, em sua transmissibilidade, em seus efeitos, mas também o objeto dessa reflexão, ou seja o pensamento ${ }^{15}$ de sua prática.

Evidentemente, se nos limitarmos apenas à questão da tradução literária, domínio que nos interessa particularmente aqui, podemos dizer desde já que todas essas premissas não refletem o estado global da prática do traduzir: elas concernem somente à diferença de atenção prestada à questão, na Europa, pelo menos.

Da mesma forma, toda a reflexão linguística ou semiológica sobre o texto literário praticada intensamente na França (ou alhures) entre o início do século XX até os anos 1960-70 não pretende ter modificado a prática escriturária, em particular a prática romanesca em sua aparência, mas ela modificou segura e consideravelmente a tendência escriturária e a atenção prestada à escrita (como pode atestar o prêmio Nobel concedido a Claude Simon). Poderíamos assim falar de convergência no sentido definido por Michel Foucault entre uma escritura e uma reflexão sobre a linguagem.

\section{A palavra. A letra}

Dizer, por conseguinte, que a primeira alternativa não nos interessa, ou seja, a tradução "servil" doméstica ou comercial, nos obriga a explicitar os valores que parecem dever se definir e se defender em favor da segunda posição.

Essa última, amplamente sustentada hoje em dia pelo texto que Walter Benjamin nos deixou como um legado, ou enigma, pressupõe que se

15 Aqui o "pensamento" remete à "reflexão" supracitada. 
tente, afim de que ela nos gratifique pelo trabalho prático que somos quotidianamente levados a fazer, a tradução literária, explicitar ao menos duas noções que qualifiquei acima de "paramétricas".

A primeira é a palavra, "elemento originário do tradutor", que não se confunde com a "letra", apesar de estreitamente ligado, como o é a metáfora à metonímia.

O que Benjamin diz é que a palavra se destaca como elemento original (unidade?) da tradução a partir de uma transposição literal da sintaxe (frase?):

“É o que obtém antes de tudo a literalidade na transposição da sintaxe, e precisamente, ele mostra que a palavra, não a proposição, é o elemento original do tradutor" ("Mito e Violência") ${ }^{16}$.

Desse modo, o "verdadeiro" tradutor deve, a fim de preservar a pureza do original, em sua diferença da língua do traduzir, renunciar a traduzir a proposição, que, ela, sustenta o sentido ("o conteúdo inessencial") para se ater à palavra como único suporte. $\mathrm{O}$ exemplo de Hölderlin nos permite melhor definir esse suporte.

Por outro lado, se a gramática (a sintaxe) é o que define, em última instância, o caráter específico de uma língua em oposição a uma outra, o privilégio dado à palavra na hipótese benjaminiana deve levar diretamente à noção de literalidade. A literalidade é a pedra de toque da tradução poética contemporânea, mas também a "pedra no caminho" dos adeptos desta alternativa.

O texto de Alain citado por Berman ${ }^{17}$ representa ao mesmo tempo a posição mais extrema e a mais fecunda do que seria a literalidade ideal ("tenho em mente que se pode sempre traduzir um poeta, inglês, latim ou grego, exatamente palavra por palavra, sem acrescentar nada, e mantendo a mesma ordem..."). Sabemos o quanto essa posição contém de provocação e

\footnotetext{
${ }^{16}$ Paul de Man retoma essa discussão ao insistir na distinção entre Wort (palavra) e Satz (frase, princípio, proposição). Wort não deve ser entendido somente como a unidade lexical, "mas também como sintaxe e como gramática". Para Benjamin, prossegue de Man, a compatibilidade entre gramática e sentido é posta em questão: a partir do momento em que uma tradução é literal (wortlich), o sentido desaparece, ver "Conclusions : 'La Tâche du traducteur' de Walter Benjamin", in Autour de La Tâche du traducteur, Dijon, TH. TY., p. 13-48. A questão é, sem dúvida, mais complexa. O texto francês de "La Tâche du traducteur", se encontra no volume Mythe et Violence, coll. Les Lettres Nouvelles, Paris, Denoël, 1971.

${ }^{17}$ op. cit., p. 45.
} 
até que ponto podemos segui-la (ver a diferença entre o Fremdes e o Fremdheit estabelecida por Humboldt $\left.{ }^{18}\right)$, mas seria completamente errôneo interpretála como a tradução "palavra por palavra" agramatical, exercício praticado por Marc Twain na sua tradução francesa da "Grenouille"19... Inversamente, literal não significa tampouco preferir uma tradução de palavras isoladas (substantivos, adjetivos, advérbios, etc...)

Dito isso, podemos estabelecer que as traduções literais, ou seja aquelas nas quais encontramos o maior respeito pela letra original, não o são da mesma maneira, e seria interessante analisarmos as diferenças de literalidade que caracterizam as traduções de Hölderlin, Chateaubriand, Jaccottet, Klossowski, Michel Deguy, Jacques Roubaud, Odorico Mendes, Augusto e Haroldo de Campos, Ezra Pound, Octavio Paz ${ }^{20}$, entre tantos outros.

Com efeito, o que entendem eles ao pretender traduzir literalmente? Quais foram os critérios adotados? De que maneira captaram a maneira original e originária de "visar o visado"? O exemplo de Chateaubriand é eloquente de uma tradução literal "bem-sucedida", apesar de muito menos radical do que a tradução de Hölderlin.

Pois, apesar de se apresentar em prosa (ou em "não-verso", como diria Jacques Roubaud), ao passo que o Lost Paradise de Milton foi escrito em versos, a tradução de Chateaubriand leva em conta as próprias fontes "literárias" do projeto miltoniano, ou seja, as referências à Bíblia em latim ou em hebraico, ou as citações latinas de Aristóteles ${ }^{21}$.

Em segundo lugar, ela respeita diferentes níveis de "estranheza", do texto original. De maneira que Chateaubriand cria palavras novas lá onde Milton o faz (a língua do poeta é estrangeira em sua própria língua); respeita a sintaxe inglesa (a língua do poeta é "estrangeira" em relação à língua do traduzir), mesmo tendo de "forçar" a sintaxe francesa e se dirige, enfim, para

\footnotetext{
${ }^{18}$ Fremdes: objeto estrangeiro/Fremdheit : coloração estrangeira, obtida pela tradução, menos significativa do que o próprio objeto.

${ }^{19}$ Ver Mark Twain, "The jumping frog of Calaveras County", tradução e retradução (palavra por palavra) do francês ao inglês e do inglês ao francês, in Change, n.14, 1973, p. 163.

${ }^{20}$ Ver Inês Oseki-Dépré, De Walter Benjamin à nos jours, Paris, Honoré Champion, 2006, onde se distingue diferentes interpretações da literalidade.

${ }^{21}$ Ver Antoine Berman, "Chateaubriand traducteur de Milton", Tours de Babel., op.cit., p. 112.
} 
o fundo virtual comum das fontes do poema miltoniano e da cultura francesa (a tradição comum é traduzida).

Ele permanece, sem dúvida, mais próxima da letra, no sentido da "materialidade" do signo articulado, do que Hölderlin, e se obtém uma forma nova (mas toda tradução não é uma forma?), talvez por ser em prosa, Chateaubriand obtém uma forma menos marcada, menos poética do que a de Antígona, especialmente inventada para isso. Poderíamos tentar talvez a partir daí - esboçar a formulação de uma relação contraditória entre dependência e literalidade? As traduções de Hölderlin, o maior dentre os tradutores segundo Walter Benjamin, foram objeto de vários estudos, análises e comentários, e podemos até pensar que o texto de Benjamin em sua totalidade faz referência a ela.

Compreendemo-lo melhor ao analisarmos o trabalho empreendido por Hölderlin para traduzir a tragédia grega; a definição da palavra como elemento originário do tradutor, assim como a da transposição sintáxica literal, adquire uma nova dimensão quando as re-situamos no contexto da expressão hölderliniana.

É assim que o poeta alemão forja não somente uma língua bastante diversificada para traduzir a diversidade e a riqueza da língua de Sófocles, mas também uma forma poética nova na medida em que forma alguma existente é suscetível de acolher a tragédia sofocleana. Seu método é dialético: de um lado, "supraliteral", segundo Haroldo de Campos ("A palavra vermelha de Hölderlin"22, ...), caracterizada por uma literalidade "exponencializada" na forma (mais do que no conteúdo) do original. Hölderlin traduz as palavras gregas no sentido próprio e figurado ao mesmo tempo (por exemplo, o famoso kalkháino, a palavra "que se turva de vermelho"), tal como Pound (para os caligramas chineses). Por outro lado, ele transcende o texto para ir buscar além, a verdadeira mensagem de Sófocles, com quem Hölderlin se sente em Immigkeit (intimidade). De maneira que podemos falar aqui de apropriação poética e de re-criação (trans-or-mistranslation, segundo Pound) "na força mais concreta da metáfora" (Haroldo de Campos, op. cit.). Nesse sentido, Hölderlin é mais

${ }_{22}$ Haroldo de Campos, “A palavra vermelha de Hölderlin”, in A Arte no horizonte do provável. São Paulo: Perspectiva, 1975, p. 93-107. 
revolucionário e mais literal do que Chateaubriand e é, sem dúvida, a razão pela qual Bertolt Brecht (1947) e Karl Orff (1951) escolheram sua versão da Antígona para as próprias adaptações teatrais e musicais.

\section{A estranheza (ou extraneidade) benjaminiana}

Percebe-se, após essa apresentação, que a questão da literalidade está longe de ser esgotada, e que o que aparece como "novo" numa tradução, ou seja, o fator propriamente "poético" (enquanto materialização de uma relação autêntica de um sujeito à linguagem, Lacan, Psychoses), pode provir igualmente da maneira pela qual o tradutor concebeu o projeto original (l'Übertragung) tanto quanto da maneira pela qual o texto se inscrevia desde o início em sua língua e em sua literatura (l'Übersetzung, verbalização do autor).

Em outras palavras, a famosa "impulsão" ou "comoção" estrangeira, definida por Pannwitz como o elemento a preservar na tradução, pelo amor pela letra, é já a resultante de diversos fatores que poderíamos caracterizar da seguinte maneira:

(a) um fator gramatical: a língua original é estrangeira em relação à língua do traduzir. Se Chateaubriand escolhe a conivência em relação à sintaxe inglesa de Milton, isso obedece a critérios poéticos que lhes são próprios, mas a questão pode se colocar diferentemente para as traduções do japonês, do chinês, do russo, etc., ou de qualquer língua inteiramente estrangeira ao francês, por exemplo.

Por outro lado, se, como pretende Jacques Lacan²3, "não existe língua alguma para a qual se coloque a questão de sua insuficiência a cobrir o campo do significado, sendo um efeito de sua existência de língua que ela nela responda a todas as necessidades", o tradutor literal não tem outra alternativa senão a de preencher, inventando, as "incorrespondências" entre as duas línguas.

A tradução oferece aqui um duplo aspecto, o da metáfora ("uma palavra por uma outra"), mas igualmente o da metonímia ("uma palavra após a outra"), ou seja, uma organização significante diferente.

\footnotetext{
${ }^{23}$ Jacques Lacan, "A instância da letra inconsciente", Écrits, Paris, Seuil, p. 429), trad. portuguesa (Inês Oseki-Dépré), Escritos, S. P., Ed. Perspectiva, p. 228.
} 
A evidência desse fator é ilusória, pois a questão é largamente eludida numa grande parte das traduções nas quais se procede mais a uma domesticação do sentido ("aclimatação", segundo Blanchot) em suas formas estereotipadas e convencionais da língua do traduzir do que a invenção literal de uma nova língua. É nesse ponto que se mede o grau de literalidade da tradução;

(b) um fator poético: a língua estrangeira é próxima da língua do traduzir mas não da língua do autor.

O que é estrangeiro aqui é o poeta, Joyce, Guimarães Rosa, Mallarmé etc., em primeiro lugar em sua língua. A literalidade se torna inseparável de seu corolário, a liberdade do tradutor, pois a ele incumbe uma dupla tarefa, a de se apropriar do projeto poético original e a de inventar ou de escolher a forma na qual o objeto poético aparecerá na outra língua. A tradução pode, nesse caso, aparecer como uma obra-prima literária tanto por sua novidade formal quanto por sua inscrição na trama literária nacional ou universal. É o caso da tradução intertextual, da qual podemos citar como exemplo a tradução do "Soneto em X", de Mallarmé, por Octavio Paz, não em espanhol mas no espanhol de Góngora. À dificuldade de traduzir a novidade do soneto mallarmeano, o poeta acrescenta uma outra, em contraponto, fazendo assim dialogarem duas línguas, duas épocas, duas poéticas numa terceira, nova;

(c) um terceiro fator, poético-gramatical, que resulta da combinação dos dois fatores anteriores. O texto é estrangeiro em sua língua e sua língua é estrangeira à língua do traduzir.

É o caso de Sófocles para Hölderlin, ou ainda de Liu Ch'e (poeta chinês do século 3 a.C.) para Ezra Pound, ou de Omar Kháyyám (1049-1131) para Edward Fitzgerald ou Augusto de Campos.

Sem entrar numa análise detalhada dos exemplos citados, podemos observar que eles provocaram efeitos bastante interessantes no plano poético: uma nova forma poética na qual "o sentido formal aparece, na tradução, semantizado", segundo Haroldo de Campos²4; uma poética nova, a poética "imagista" ou "vorticista", para o poeta americano, pai do pós-

\footnotetext{
${ }^{24}$ Haroldo de Campos, op. cit., p.99.
} 
modernismo poético; a abertura de um novo espaço intertextual para o poeta brasileiro, que, em resposta à tradução de Fitzgerald (o único bom poema da época", segundo Ezra Pound em $A B C$ da literatura ${ }^{25}$ ), ela mesma inscrita num espaço intertextual em suas alusões a Shakespeare;

\footnotetext{
"Ah, make the most of what we yet may spend,

Before we too into the Dust descend:

Dust into Dust, and under dust, to lie,

Sans Wine, sans song, sans Singer - and sans End!"26
}

Em sua tradução, Augusto de Campos presta homenagem a duas figuras geniais da contemporaneidade brasileira, João Gilberto e João Cabral de Melo Neto ("Se diz a palo seco/ o canto sem guitarra:/ o cante sem: o cante/ o cante sem mais nada"):

\footnotetext{
"Ah, vem, vivamos mais que a Vida, vem,

Antes que em Pó nos deponham também,

Pó sobre Pó e sob o Pó, pousados,

Sem Cor, sem Sol, sem Som, sem Sonho - sem!"
}

A literalidade é fundamental nesse terceiro caso de figura, apesar do paradoxo aparente dessa afirmação. A tradução é tão mais próxima da letra original quanto ela se torna ela mesma criação original: não somente tradução da letra, mas tradução da tradição da letra.

Tradição não se deve confundir aqui com uma posição tradicional, mas se entender no sentido da "chama" a preservar através dos tempos, no sentido da divisa poundiana do criticism by translation: "Make it new".

A questão da perda do sentido pode ser colocada de outro modo: o que se perde, na realidade, nunca existiu. O que se perde nessa acepção da

\footnotetext{
${ }^{25}$ Ezra Pound, $A B C$ da literatura, S. P., Cultrix, 2010.

${ }^{26}$ Shakespeare: "Sans teeth, sans eyes, sans taste, sans everything", As you like it, ato II, cena 7).
} 
tradução literal, é a possibilidade de traduzir o "velho" no novo, de reduzir ou de converter o poético ou a estranheza em moeda corrente.

O que o tradutor não pode traduzir é a significação da obra para os contemporâneos, tais como ressonâncias, conotações, associações extralinguísticas, em suma, tudo o que constitui o contexto de produção cultural de uma dada obra num dado momento. É, portanto, ao tradutor que incumbe criar um novo espaço no qual sua tradução encontrará o seu lugar.

O privilégio da palavra não se deve entender nos termos estreitos, antissintáticos, visto que não se trata de privilegiar palavras isoladas, substantivos, substanciais ou aparentemente poéticos, como já foi dito, mas, bem ao contrário, de visar, além do eixo metonímico, horizontal e necessário, igualmente a dimensão metafórica, vertical e polifônica do texto literário.

Fim

\section{Comentário:}

O artigo supra foi escrito numa intenção senão "polêmica", certamente "programática", na medida em que defende a tradução tornada para a fonte, mas levando em conta uma série de etapas: a literalidade aqui reivindicada é uma literalidade "não literal" no sentido da "palavra por palavra", mas uma tradução que leva em conta a "letra" do texto, em última instância, sua materialidade e sua história, o que me permite incluir Haroldo de Campos ou Ezra Pound no paradigma dos "verdadeiros" tradutores. Ele deve muito à leitura de Benjamin através de Antoine Berman, no tocante à letra, à estranheza, e à finalidade dos estudos tradutológicos, sem que se possa falar de influência, mas, no caso: de confluência.

Os exemplos de Hölderlin e de Chateaubriand são inspirados respectivamente pelas análises de Benjamin (Hölderlin) e de Antoine Berman $^{27}$, que considera o autor francês como o maior tradutor de todos os tempos. Em ambos os casos, sem falar de metodologia, a maneira de se referir a uma "literalidade" diacrônica (a referência à Bíblia em Chateaubriand, a referência a Sófocles, no caso de Hölderlin) é

27 “Chateaubriand traducteur de Milton”, Les Tours de Babel, T.E.R., 1985, p. 109-125. 
extremamente produtiva para os estudos da tradutologia. Assim, é possível considerar a tradução do soneto em " $X$ ", de Mallarmé por Octavio Paz de certo modo "literal", não no stricto sensu, mas no modo como para o poeta mexicano, o parentesco entre esse soneto e Góngora lhe permite traduzi-lo de maneira "gongoresca" 28 .

Do mesmo modo, é possível ver na tradução de "The Hunting of the Snark", de Lewis Carroll por Jacques Roubaud, aparentemente distante do original, um exemplo de literalidade diacrônica. Com efeito, Roubaud opera uma série de transformações, tais como a substituição em francês da quadra de Carroll pela sextilha ou a supressão da pontuação original - traços que poderíamos considerar como imprescindíveis numa tradução literal -, obtendo um resultado surpreendente, na medida em que a sextilha, forma arcaica, autoriza a heterometria, e constitui uma referência ao passado da métrica francesa. ${ }^{29}$ Da mesma forma, ele substitui as rimas - bastante acentuadas na versão original - por assonâncias (seguindo as prescrições de Mallarmé) e introduz espaços brancos que significam as pausas e que marcam o ritmo de maneira diferente. Essas traduções podem ser consideradas como "isomorfas", segundo Haroldo de Campos, outro grande leitor de Walter Benjamin.

A importância da noção de reflexão vem diretamente de Antoine Berman, no seu ensaio "La traduction et la lettre ou l'auberge du lointain" ("A tradução e a letra ou o albergue do longínquo".) Podemos ler: "A tradução é uma experiência que pode se abrir e se (re)apreender na reflexão. Mais precisamente: ela é originalmente (e enquanto experiência) reflexão". Ele insiste, entretanto, em diferenciá-la da "descrição impressionistas dos processos subjetivos do ato de traduzir, nem uma metodologia" ${ }^{30}$. A nosso ver, a inscrição da reflexão no processo analítico da tradução é um dos

${ }^{28}$ Ver Inês Oseki-Dépré, "Octavio Paz: traduction et transformation", in Théories et Pratiques de la traduction littéraire. Paris: Armand Collin, 1999 (2e édtion 2006), pp. 112-115.

${ }^{29}$ Ver Inês Oseki-Dépré, "Jacques Roubaud traducteur", in Jacques Roubaud compositeur de mathématique et de poésie, 2010, Absalon (com a participação de ATILF-CNRS e do Instituto Universitário francês), p. 221233.

${ }^{30}$ Antoine Berman, "La traduction et la lettre ou, l'auberge du lointain", Les Tours de Babel, op. cit., p. 37 e 39. 
pontos fortes da tradutologia bermaniana, que não poderá mais se limitar à descrição das transformações entre original e tradução, mas que necessitará de uma articulação interdisciplinar. Berman associa sua reflexão à psicanálise (com a noção de "sujeito" ${ }^{31}$ ) e à hermenêutica (a significação literária do texto). Quanto a nós, vemos na reflexão uma maneira de articular o texto traduzido à literatura em geral (literatura comparada), como uma forma de crítica e de poética de um novo tipo.

Dito isso, na terceira parte do ensaio ("analítica da tradução e a sistemática da deformação"32), com o intuito de analisar as diferentes tendências deformantes da tradução, Antoine Berman enumera e descreve treze modos de "infidelidade" que devem ser evitadas na prática do traduzir. Aqui, novamente, sem pretender a uma metodologia, as sugestões de Antoine Berman constituem um protocolo interessante no interior da pedagogia tradutológica.

Ora, se observarmos a história da constituição da língua francesa desde o édito de François I (Ordonnance de Villers-Cotteret, 1539), que a institui como língua oficial prevalecendo sobre o latim ou o dialeto, podemos observar que, ao longo dos séculos, houve várias prescrições emanando de gramáticos ou de autoridades acadêmicas em favor de procedimentos e de regras sobre a melhor maneira de traduzir. O objetivo desse arsenal, inspirado pelos autores clássicos (Cícero, Horácio) foi sempre o de criar ou manter uma língua nobre, bela, elevada. ${ }^{33}$

Antoine Berman inverte, de certa maneira, o sistema de prescrições clássicas chamando-o de "sistemática de deformações". O que era obrigatório no passado, e que permaneceu até pouco tempo na prática tradutiva, deve ser condenado, como a racionalização, a clarificação, o alongamento, o enobrecimento, o empobrecimento qualitativo ou

\footnotetext{
${ }^{31}$ Ver Inês Oseki-Dépré, "Subjectivité et Sujet de la traduction”, onde distingo a subjetividade de Charles Baudelaire, manifesta, influenciada pelo contexto social, pela sua admiração por Edgar Allan Poe e o Sujeito Baudelaire que, em sua tradução em prosa, elabora inconscientemente a forma do que seriam os Poemas em Prosa (ou o Spleen de Paris), in De Walter Benjamin à nos jours, Paris, Honoré Champion, 2007, p. 177-202.

32 Ver Antoine Berman, "L'analytique de la traduction et la systématique de la déformation", in Les Tours de Babel, op. cit., p. 65-82

33 Ver Inês Oseki-Dépré, "Les théories prescriptives", cap. 1, Théories et Pratiques de la traduction littéraire, Paris, Armand Colin, 1999 (2a edição 2006), p. 19-44.
} 
quantitativo, a homogeneização, a destruição dos ritmos, das redes significantes subjacentes, dos sistematismos, das redes da língua falada, das locuções e a abolição das superposições linguísticas ${ }^{34}$. Na verdade, trata-se da destruição do estilo, da singularidade do texto original, talvez da sua "estranheza".

A estranheza ou "extraneidade" é a noção-chave da tradutologia bermaniana e provém indiscutivelmente da "tarefa" benjaminiana.

Segundo o filósofo alemão, com efeito, se referindo a Pannwitz ${ }^{35}$, extraneidade e literalidade são correlativas.

Segundo Pannwitz:

O erro fundamental do tradutor é de manter o estado fortuito de sua própria língua em vez de se deixar guiar intensamente pela língua estrangeira. Sobretudo quando ele traduz de uma língua suficientemente distante, é-lhe preciso retornar aos elementos primordiais da própria linguagem, lá onde se encontram palavra, imagem, som; é-lhe preciso distender e aprofundar sua própria língua graças à língua estrangeira; não se imagina até que ponto a coisa é possível; até que ponto uma língua pode se transformar; de língua a língua não existe distância maior do que de dialeto a dialeto, mas isso não quando o levamos de maneira leviana, mas ao contrário quando os levamos suficientemente a sério.

Para Antoine Berman, o uso de "dialeto" em vez de língua em Benjamin é significativo de dois desenvolvimentos, as línguas são dialetos em relação à Língua pura (Reine Sprache), por conseguinte, as línguas são manifestações orais e não escritas. ${ }^{36}$ É essa oralidade que cabe ao tradutor manter na sua tradução, é a essa estranheza que Benjamin faz referência na tradução da Antígona por Hölderlin. É o que ele chama de vernacular.

É a abertura ao Outro, questão primordial da qual se trata para Antoine Berman, em sua visão ética da tradução. E esse Outro se revela tanto pelos particularismos da língua a traduzir quanto por uma intertextualidade

\footnotetext{
${ }^{34}$ As três primeiras tendências deformantes correspondem assim ao que Etienne Dolet (o primeiro "tradutólogo" francês) enunciava no Século 16 como prescriçōes.

${ }^{35}$ Rudolph Pannwitz (1881-1969), pensador alemão próximo de Nietzsche, autor de $A$ crise da cultura européenne (1917), citado por Walter Benjamin, "A tarefa do tradutor", op. cit..

${ }^{36}$ Ver Antoine Berman, L'âge de la traduction, col. Intempestives, Paris, Presse Universitaires de Vincennes, p. 178-181. O livro é inteiramente consagrado à "Tarefa do tradutor", que Berman decifra palavra por palavra.
} 
diacrônica, como no caso de Octavio Paz traduzindo Mallarmé ou de Klossowski traduzindo a Eneida de Virgílio. ${ }^{37}$

Em conclusão, neste artigo apresentado em Arles, foram evocados os aspectos essenciais da tradutologia, tal como Antoine Berman preconizou durante toda a sua carreira de crítico e de pensador. Suas intuições explicam a extensão do domínio da reflexão sobre a tradução literária, que engloba a questão da re-tradução (em diacronia: a Eneida, de Virgílio e em sincronia: Going to bed, de John Donne); a questão do conflito entre horizonte de espera e sujeito da tradução (Baudelaire e Poe); a questão da tradução e o autocomentário; a questão da má tradução; a questão da loucura.

Mais do que um domínio, a tradução se torna desde então, uma maneira de pensar.

Aix-en-Provence, fevereiro 2021.

\section{Références}

BERMAN, Antoine et al. Les tours de Babel: essais sur la traduction. Mauvezin: Trans-Europe-Repress, 1985.

BERMAN, Antoine. La traduction et la lettre ou l'auberge du lointain. Mauvezin: Trans-Europe-Repress, 1985.

BERMAN, Antoine. L'Âge de la traduction. "La tâche du traducteur" de Walter Benjamin, un commentaire. Paris: Presses Universitaires de Vincennes, coll. Intempestives, 2008.

BITSORIS, Vanghélis. Le projet de traductologie d'Antoine Berman. In BRODA, Martine (dir.). La traduction-poésie - À Antoine Berman. Strasbourg: Presses Universitaires de Strasbourg, 1999, p. 49- 67.

${ }^{37}$ Ver Antoine Berman, "l'Enéide de klossowski”, in Les Tours de Babel, op.cit., p. 127-150. 
CAMPOS, Haroldo de. A palavra vermelha de Hölderlin. In . A Arte no horizonte do provável e outros ensaios. São Paulo: Perspectiva, 1975, p. 93107.

CRESTA, Michel. Au-dessus de fragments d'un language plus grand: pour une introduction à la Tache du Traducteur de Walter Benjamin. Littoral, Paris, v. 13, Traduction de Freud, transcription de Lacan, p. 53-62, jun. 1984.

LACAN, Jacques. A instância da letra inconsciente. In: Escritos. Trad. Inês Oseki-Dépré. São Paulo: Perspectiva, 1990.

OSEKI-DÉPRÉ, Inês. Théories et Pratiques de la traduction littéraire. Paris: Armand Collin, 1999 (2e édtion 2006).

OSEKI-DÉPRÉ, Inês. Subjectivité et Sujet de la traduction. In: De Walter Benjamin à nos jours. Paris: Honoré Champion, 2007, p. 177-202.

OSEKI-DÉPRÉ, Inês. Jacques Roubaud traducteur. In: DISSON, A.; MONTÉMONT, V. (dir.). Jacques Roubaud compositeur de mathématique et de poésie. Charenton-le-Pont: Absalon, 2010, p. 221-233.

POUND, Ezra. ABC da literatura. São Paulo: Cultrix, 2010.

\section{Resumo}

Nesse artigo tenta-se situar a origem da disciplina conhecida desde os anos 80 na França pelo nome de tradutologia, domínio do conhecimento, interdisciplinar, tal como preconizou Antoine Berman, seu promotor. O artigo põe em relevo as principais noções introduzidas pelo filósofo na construção do modelo da disciplina ou do território: uma hermenêutica, rica de reflexão e análises, cujo fito não seria o de julgar as traduções mas de considerá-las em sua essência por meio de uma leitura reflexiva que leva em conta a palavra, a letra do texto a traduzir, que não exclua, ao contrário, a estranheza do original. $\mathrm{O}$ artigo expõe o diálogo entre o pensamento de Antoine Berman e a autora, ambos influenciados pela "Tarefa do tradutor" de Walter Benjamin, cujos percursos, paralelos durante muitos anos, acabam se distanciando num ponto: a hermenêutica para o primeiro, a poética para a segunda. Nesse sentido, é inserido o texto proposto pela autora numa assembleia de tradutores, que se dirige, no fundo, ao seu interlocutor privilegiado, Antoine Berman. 
Palavras-chave: Tradutologia; Hermenêutica; Leitura reflexiva; Letra; Estranheza.

\section{Résumé}

Dans le présent article on tente de situer l'origine de la discipline connue depuis les années 80 en France sous le nom de traductologie, domaine de la connaissance, interdisciplinaire, ainsi que la définie Antoine Berman, son promoteur. L'article met em relief les principales notions introduites par le philosophe dans la construction du modele de la discipline ou du territoire: une herméneutique, riche de réflexions e d'analyses, dont le but ne serait pas de juger les traductions mais de les considérer dans leur essence au moyen d'une lecture réflexive, qui prenne em compte le mot, la lettre du texte à traduire, qui n'exlue pas, au contraire, l'étrangeté de l'original. L'article expose le dialogue entre la pensée d'Antoine Berman et l'autrice, tous deux influencées par la "Tâche du traducteur" de Walter Benjamin et dont les parcours, paralallères durant longtemps, finissent par s'éloigner sur un point: l'herméneutique pour le premier, la poétique pour la seconde. Dans ce sens, y est inséré le texte proposé par cette dernière lors d'une assemblée de traducteurs qui s'adresse, au fond, à son interlocuteur privilégié, Antoine Berman.

Mots-clés: Traductologie; Herméneutique; Lecture réflexive; Lettre; Etrangeté. 
Inis

jis souhante d'obord une exullente et riche a uneé. Et eusvita, jè te remencée pou tanticle, pui d'une purt meflotte inormement, d'autre pout - tout a fairt a pat - est absolument riessi be bout en bout. Je sris coment pue tm siminane sille birn. Taib-tu courme moi des brovillas cunftrs et communicables? On (un iditeer de toulouse) ve publien (pinpre) totreili de uom preenies seminaine.

$$
\text { Sobelle est tros fatigué è sx zime (it denii) nois de }
$$
joossese, meis vein d'dermom. Sinm, proboblemont, le poids de $l^{\prime}$ ge at touts bes craintes efferents. Elle devait alles en Aresentmi

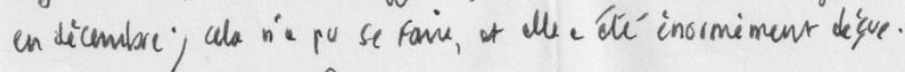
Vos -to venue e paris?

Je commence la semaine prochernè mon commention

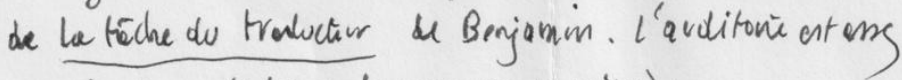
novori (une vingtaine Ue persounes au moins).

le travace de Coumisoriat or absabaut at interessant. voila, cirtuit juste un petit mot pourte romeneier. fe t'miniens

\section{Antome}

$$
\begin{aligned}
& \text { PS. Quid de ma mlicle in drage? } \\
& \text { Et Hutchinsm? }
\end{aligned}
$$

